\title{
Derived Interaction Parameters for the TSAI- WU Tensor Polynomial Theory of Strength for Composite Materials
}

S. J. DeTeresa, G. J. Larsen

This article was submitted to 2001 American Society of Mechanical Engineers International Mechanical Engineering Congress \& Exposition, New York, N.Y., November 11-16, 2001

U.S. Department of Energy

Lawrence Livermore National Laboratory

August 3, 2001 


\section{DISCLAIMER}

This document was prepared as an account of work sponsored by an agency of the United States Government. Neither the United States Government nor the University of California nor any of their employees, makes any warranty, express or implied, or assumes any legal liability or responsibility for the accuracy, completeness, or usefulness of any information, apparatus, product, or process disclosed, or represents that its use would not infringe privately owned rights. Reference herein to any specific commercial product, process, or service by trade name, trademark, manufacturer, or otherwise, does not necessarily constitute or imply its endorsement, recommendation, or favoring by the United States Government or the University of California. The views and opinions of authors expressed herein do not necessarily state or reflect those of the United States Government or the University of California, and shall not be used for advertising or product endorsement purposes.

This is a preprint of a paper intended for publication in a journal or proceedings. Since changes may be made before publication, this preprint is made available with the understanding that it will not be cited or reproduced without the permission of the author.

This work was performed under the auspices of the United States Department of Energy by the University of California, Lawrence Livermore National Laboratory under contract No. W-7405-Eng-48.

This report has been reproduced directly from the best available copy.

Available electronically at http://www.doc.gov/bridge

Available for a processing fee to U.S. Department of Energy

And its contractors in paper from

U.S. Department of Energy

Office of Scientific and Technical Information

P.O. Box 62

Oak Ridge, TN 37831-0062

Telephone: (865) 576-8401

Facsimile: (865) 576-5728

E-mail: reports@adonis.osti.gov

Available for the sale to the public from

U.S. Department of Commerce

National Technical Information Service

5285 Port Royal Road

Springfield, VA 22161

Telephone: (800) 553-6847

Facsimile: (703) 605-6900

E-mail: orders@ntis.fedworld.gov

Online ordering: http://www.ntis.gov/ordering.htm

OR

Lawrence Livermore National Laboratory

Technical Information Department's Digital Library

http://www.llnl.gov/tid/Library.html 


\title{
DERIVED INTERACTION PARAMETERS FOR THE TSAI-WU TENSOR POLYNOMIAL THEORY OF STRENGTH FOR COMPOSITE MATERIALS
}

\author{
Steven J. DeTeresa \\ Gregory J. Larsen \\ Manufacturing and Materials Engineering Division \\ Mechanical Engineering Department \\ Lawrence Livermore National Laboratory \\ 7000 East Avenue \\ Livermore, CA 94551
}

\begin{abstract}
It is shown that the two interactive strength parameters in the Tsai-Wu tensor polynomial strength criterion for fiber composites can be derived in terms of the uniaxial or non-interacting strength parameters if the composite does not fail under practical levels of hydrostatic pressure or equal transverse compression. Thus the required number of parameters is reduced from seven to five and all five of the remaining strength terms are easily determined using standard test methods. The derived interactive parameters fall within the stability limits of the theory, yet they lead to open failure surfaces in the compressive stress quadrant. The assumptions used to derive the interactive parameters were supported by measurements for the effect of hydrostatic pressure and unequal transverse compression on the behavior of a typical carbon fiber composite.
\end{abstract}

\section{INTRODUCTION}

Despite the widespread use of fiber composite materials in structural applications, an outstanding problem is the lack of consensus on a single, experimentally validated theory for failure. For reasons of simplicity, the most common approach to predicting failure is through the use of limit theories such as maximum stress or maximum strain. While these theories provide a means to assess the mode of failure, they do not address the interactive effects that have been observed for polymer-based composites. A popular and arguably the next most utilized failure criterion is the Tsai-Wu tensor polynomial theory [1] This strength criterion is a simplified version of the scalar relation involving expansion of the stress tensor, which was first proposed by Gol denblat and Kopnov [2]. These polynomial strength criteria do provide for interactive stress effects, which is both a benefit and a burden. The latter is due to the interactive strength terms that up till now could only be determined by combined stress tests. In this paper it will be shown for materials that do not fail under hydrostatic compression or equal transverse compression, that the two interactive strength terms in the Tsai-Wu criterion can be derived from the commonly measured uniaxial strengths. Experimental results to support these assumptions will be given for a typical carbon fiber composite. 


\section{TSAI-WU TENSOR POLYNOMIAL FAILURE CRITERION}

The Tsai-Wu failure theory is based on the expansion of the stress tensor, truncated at second order terms to give

$$
F_{i} \sigma_{i}+F_{i j} \sigma_{i} \sigma_{j} \leq 1
$$

For this relation $F_{i}$ and $F_{i j}$ are the strength parameters and the contracted notation is used where $i, j=1,2, \ldots 6$. When the theory is applied to a unidirectional composite lamina, which is assumed to transversely isotropic with the normal to the plane of isotropy (fiber direction) in the 1-direction, the expanded form of (1) becomes

$$
\begin{gathered}
F_{1} \sigma_{1}+F_{2}\left(\sigma_{2}+\sigma_{3}\right)+F_{11} \sigma_{1}^{2}+2 F_{12} \sigma_{1}\left(\sigma_{2}+\sigma_{3}\right)+F_{22}\left(\sigma_{2}^{2}+\sigma_{3}^{2}\right) \\
+2 F_{23} \sigma_{2} \sigma_{3}+F_{44} \sigma_{4}^{2}+F_{55}\left(\sigma_{5}^{2}+\sigma_{6}^{2}\right) \leq 1
\end{gathered}
$$

where

$$
F_{44}=2\left(F_{22}-F_{23}\right)
$$

For the common case of plane stress, $(2)$ is reduced to

$$
F_{1} \sigma_{1}+F_{2} \sigma_{2}+F_{11} \sigma_{1}^{2}+2 F_{12} \sigma_{1} \sigma_{2}+F_{22} \sigma_{2}^{2}+F_{55} \sigma_{5}^{2} \leq 1
$$

The strength terms $F_{i}$ and $F_{i i}$ are determined directly from the uniaxial strengths of the lamina using

$$
F_{11}=\frac{1}{X_{T}\left|X_{C}\right|}, \quad F_{22}=\frac{1}{Y_{T}\left|Y_{C}\right|}, \quad F_{1}=\frac{1}{X_{T}}-\frac{1}{\left|X_{C}\right|}, \quad F_{2}=\frac{1}{Y_{T}}-\frac{1}{\left|Y_{C}\right|}, \quad F_{44}=\frac{1}{S_{T}^{2}}, \quad F_{55}=\frac{1}{S_{L}^{2}}
$$

where

$$
\begin{aligned}
& X_{T}=\text { longitudinal tensile } \text { strength } \\
& X_{C}=\text { longitudinal compressive strength } \\
& Y_{T}=\text { transverse tensile strength } \\
& Y_{C}=\text { transverse compressive } \text { strength } \\
& S_{L}=\text { longitudinal shear strength } \\
& S_{T}=\text { transverse shear strength }
\end{aligned}
$$

The two remaining parameters, $F_{12}$ and $F_{23}$, are the interactive strength terms, which in general have to be determined experimentally using combined stress tests in order to apply the theory to either the full three-dimensional or the reduced plane stress cases. Very few materials have been characterized for these interactive parameters and some values for the interactive parameters are found in Wu [3], Jiang and Tennyson [4], and Kallas and Hahn [5]. Since combined stress tests are neither common nor straightforward, there has been a lack of data from which to calculate these interactive terms. Consequently the uncertainty in these terms has been a detriment to the more widespread use of the theory and to the confidence in the predictions made therefrom. In this paper it is shown that when the theory is applied to materials that do not fail under practical levels of hydrostatic compression or equal transverse compression, the two interactive terms can be specified in terms of the lamina strengths, thereby eliminating the need for complex combined stress testing.

In the original description of the theory, Tsai and Wu placed significant emphasis on maintaining closed, ellipsoidal failure envelopes for all stress states. To avoid open ended failure surfaces, stability conditions were proposed, which for transversely isotropic materials are given by

$$
\begin{gathered}
F_{11} F_{22}-F_{12}^{2} \geq 0 \\
F_{22}^{2}-F_{23}^{2} \geq 0
\end{gathered}
$$


It will be shown that open-ended hyperboloidal failure surfaces do result for certain values of the interactive terms that are within these stability limits and that allowing these open surfaces is a reasonable and experimentally supported modification of the original theory.

\section{DERIVATION OF INTERACTIVE TERMS}

To derive relations for $F_{12}$ and $F_{23}$, consider first the case of pure hydrostatic stress, which will be referred to as $p_{3 \mathrm{D}}$. Under this stress state, (2) becomes

$$
\left(F_{11}+4 F_{12}+2 F_{22}+2 F_{23}\right) p_{3 D}^{2}+\left(F_{1}+2 F_{2}\right) p_{3 D} \leq 1
$$

where $\sigma_{1}=\sigma_{2}=\sigma_{3}=p_{3 \mathrm{D}}$ and all other stresses are zero. If failure is not allowed under a compressive hydrostatic stress, then the first term in (7) must vanish

$$
F_{11}+4 F_{12}+2 F_{22}+2 F_{23}=0
$$

Tsai and Wu gave this result in their original work, but never pursued this approach as a way to specify the interactive parameters.

Next consider the case of biaxial transverse stress where $\sigma_{2}$ and $\sigma_{3}$ are the only nonzero components of the stress tensor. Then relation (2) becomes

$$
F_{2}\left(\sigma_{2}+\sigma_{3}\right)+F_{22}\left(\sigma_{2}^{2}+\sigma_{3}^{2}\right)+2 F_{23} \sigma_{2} \sigma_{3} \leq 1
$$

For the special case of equal transverse stress, $p_{2 \mathrm{D}}$, (9) becomes

$$
2\left(F_{22}+F_{23}\right) p_{2 D}^{2}+2 F_{2} p_{2 D} \leq 1
$$

If it is assumed that failure will not occur for practical levels of equal compressive transverse stress, then the first term in (10) must vanish

$$
F_{22}+F_{23}=0
$$

This result gives the interactive parameter $F_{23}$ solely in terms of the strength parameter $F_{22}$. Reexamination of the stability condition (6b) shows that relation (11) is the admissible lower limit.

Combining (11) with (8) yields the following relation for the other interactive parameter, $F_{12}$

$$
F_{12}=-\frac{F_{11}}{4}
$$

which is also defined using only a uniaxial strength parameter. Substitution of this result into the stability condition (6a) gives

$$
F_{22}-\frac{F_{11}}{16} \geq 0
$$

For most common fiber composite materials, longitudinal strengths are at least an order of magnitude greater than transverse strengths. Therefore the derived relation (12) for $F_{12}$ is well within the specified stability limit (6a).

In summary, using the assumption that failure of a composite lamina will not occur under practical levels of hydrostatic and equal transverse compression, the following relations are obtained for the two interactive parameters in the Tsai-Wu strength theory

$$
\begin{aligned}
& F_{12}=-\frac{F_{11}}{4} \\
& F_{23}=-F_{22}
\end{aligned}
$$


Despite the fact that both of these values for the interactive parameters fall within the stability limits, they result in open-ended, hyperboloidal failure surfaces in the compression stress quadrant. In the following section, experimental results are given to support the assumptions that led to these relations and to show that the requirement of closed failure surfaces, which was so strongly emphasized by Tsai and Wu, should be relaxed for certain stress states.

\section{D AND 2D COMPRESSION TESTS}

To examine behavior of a fiber composite lamina under hydrostatic and equal transverse compressive stress, unidirectional specimens of IM7 carbon fiber having a thermoplastic polyimide (K3B) matrix were prepared using manufacturer's recommended autoclave processing procedures. The resulting composite had a nominal fiber volume fraction of $60 \%$ and a void content of less than $1 \%$.

Two methods were used to assess failure under hydrostatic pressure. First, test specimens were measured for dimensional changes after exposure to high pressure using foil strain gages that were wired for temperature compensation. Strains in both the in-plane transverse and longitudinal directions were measured for both the composite and a control steel specimen. The steel is expected to remain elastic under the pressure applied and was used to check the repeatability and accuracy of the strain measurements. Second, composite specimens were also measured for the effect of exposure to high pressure on the resulting transverse compression response at ambient pressure. It was thought that if failure or damage occurred under hydrostatic pressure, it would be most detrimental to matrix-dominated properties of the composite. The specimens were exposed to a pressure of $344 \mathrm{MPa}$ for at least 15 minutes in a $0.7 \mathrm{GPa}$ pressure cell that used kerosene as the pressurizing fluid. Although the specimens were in direct contact with the pressure medium, weight change measurements after exposure confirmed that the IM $7 / \mathrm{K} 3 \mathrm{~B}$ composite was relatively inert to the kerosene

A summary of the dimensional changes after pressure exposure is given in Table 1. The data for the steel specimen shows the strain gages were not affected by exposure to high-pressure kerosene and that the resolution of the measurements was $-1 \mu$ strain. The composite dimensions were virtually unchanged in the longitudinal direction, but were diminished in the transverse direction. Measurements made $4 \mathrm{~h}$ after exposure revealed that there was some small recovery of the original dimensions. Although a permanent or plastic compression strain was observed in the transverse direction, it was very slight. For comparison, the same degree of lateral shrinkage would occur with a temperature drop of about $3{ }_{j} \mathrm{C}$. There were no obvious signs of damage to the specimen. It is believed that the compression plastic strain was simply the result of further consolidation of the material due to collapse of voids. If it is assumed that the same amount of plastic compressive strain occurred in the thickness direction, then the total volumetric plastic strain was only $-0.03 \%$ and the corresponding density increase was only $0.0004 \mathrm{~g} / \mathrm{cc}$.

\begin{tabular}{|c|c|c|c|c|c|}
\hline \multirow{4}{*}{ space } & \multirow[t]{2}{*}{$\begin{array}{c}\text { Time of } \\
\text { Measurement }\end{array}$} & \multicolumn{2}{|c|}{$\begin{array}{c}\text { Change in } 0_{i} \text { Strain Gage Value } \\
(\mu \text { strain })\end{array}$} & \multicolumn{2}{|c|}{$\begin{array}{c}\text { Change in } 90_{i} \text { Strain Gage Value } \\
(\mu \text { strain })\end{array}$} \\
\hline & & Steel & IM7/K3B & Steel & IM7/K3B \\
\hline & $\begin{array}{l}\text { Immediately After } \\
\text { Exposure }\end{array}$ & +1 & -3 & -1 & -159 \\
\hline & $4 \mathrm{~h}$ After Exposure & +1 & -11 & 0 & -142 \\
\hline
\end{tabular}

A more convincing test for failure of a lamina under hydrostatic pressure is the effect of exposure on the matrix-dominated behavior. For this examination the transverse compression strength $\left(Y_{C}\right)$ was measured on control composite specimens and specimens that had been exposed to pressure as described above. The average strengths of the control and exposed specimens were $210-3.3 \mathrm{MPa}$ and $215-3.5 \mathrm{MPa}$, respectively, which clearly shows that there was no effect of pressure on the retention of matrix-dominated strength. When taken together, the relatively small plastic compressive strain and the insensitivity of transverse compression strength to pressure both demonstrate that the composite does not fail under the level of hydrostatic compression examined here.

The second assumption that allowed for the derivation of the interactive parameters in terms of uniaxial strengths was the absence of failure under practical levels of equal transverse compression. Unlike the case of hydrostatic compression where testing is relatively straightforward, it is more difficult to test a lamina for failure under equal transverse compression. A simpler test that yields similar information about the interaction parameter is a plane strain compression test in which the lamina is compressed in a 
transverse (2-) direction and is free to move laterally only in the fiber (1-) direction. A depiction of this test is shown in Fig. 1. The stress $\sigma_{3}$ can be related to the applied stress $\sigma_{2}$ through the lamina constitutive relationships, resulting in

$$
\sigma_{3}=v_{23} \sigma_{2}
$$

where $v_{23}$ is the transverse Poisson's ratio. The stresses in plane-strain compression thus constitute an unequal transverse biaxial compression state. For most carbon fiber composites, $v_{23}$ is close to value of $1 / 2$. Substituting this value in (15) and then using the resulting stresses in (2) gives the following condition for failure under plane-strain compression

$$
\left(\frac{3}{2} F_{2}\right) \sigma_{2}+\left(\frac{5}{4} F_{22}+F_{23}\right) \sigma_{2}^{2} \leq 1
$$

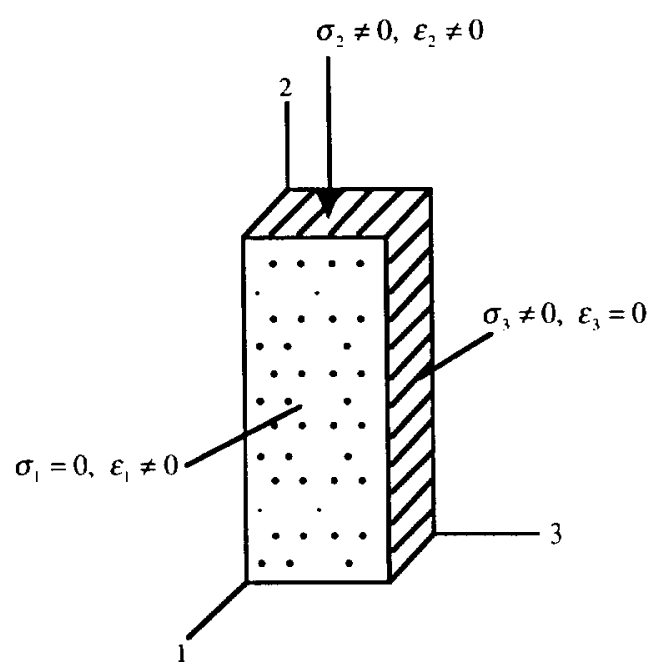

Figure 1. Plane-strain compression test to evaluate the interactive term, $F_{23}$, of the tensor polynomial failure criterion.

The stability condition (6b) limits the magnitude of $F_{23}$ to be less than or equal to $F_{22}$ and inspection of (16) shows that there is always a finite failure stress under these conditions of plane-strain compression. However, examination of the predicted failure stress for the allowable range of $F_{23}$ values shows that high strength values are attained when $F_{23}$ approaches the value given by (14b) and this behavior is shown in Fig. 2. In this plot the failure stress is normalized to the transverse compression strength $Y_{C}$ and the interactive parameter is normalized to the term $F_{22}$. It is clear from this figure that as the term $F_{23}$ approaches the limit given by (14b), there is significant strengthening of the composite.

To assess the value of the term $F_{23}$, the IM7/K3B composite was tested under both uniaxial transverse compression stress and plane-strain compression. Additionally, the pure K3B matrix material was tested in the same manner. Results for plane-strain and uniaxial compression of the matrix and the unidirectional composite are plotted in Fig. 3. In plane-strain compression, the composite was able to withstand a stress that was in excess of four times the strength $Y_{C}$ without failing. In fact the test was halted before failure because stress levels approached the yield point of the steel fixtures used to conduct the tests. Some strengthening of the neat resin was also seen in plane-strain compression, but normal yield behavior was still observed. It is interesting to note that the yield stress of the resin under plane-strain compression was close to the transverse compression strength, $Y_{C}$, of the composite. This suggests that the fiber is holding the in-situ matrix in a plane-strain condition when the composite is under a uniaxial transverse compression stress. More importantly, the significant strengthening of the composite measured under plane-strain compression shows that the interactive parameter $F_{23}$ is indeed close to the limit given by (14b). 


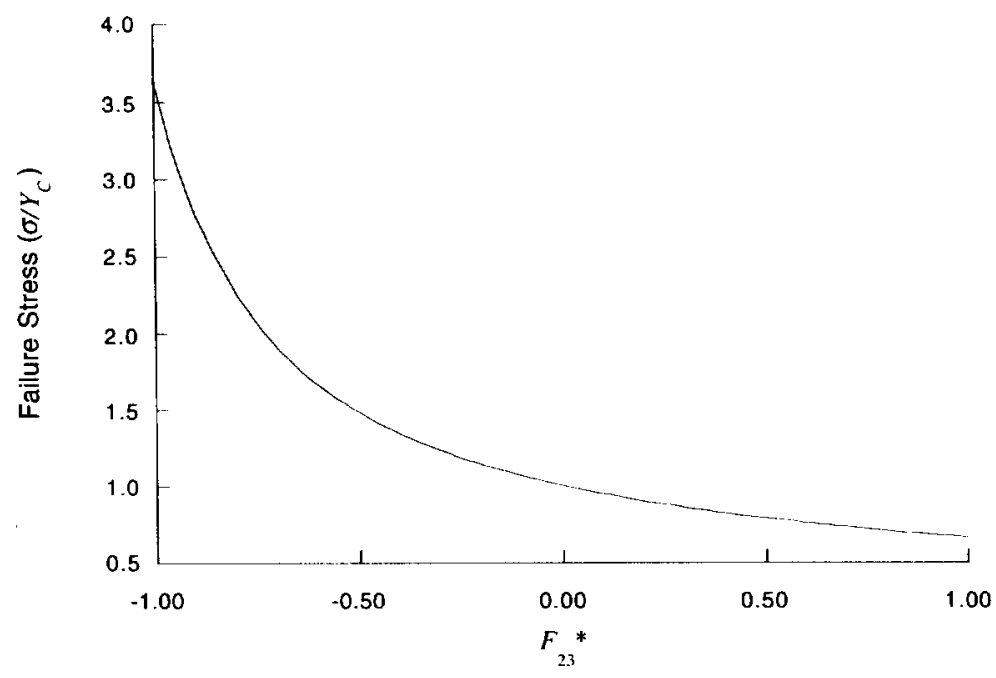

Figure 2. Dependence of the plane-strain compression strength on the interactive term, $F_{23}$, of the tensor polynomial failure criterion.

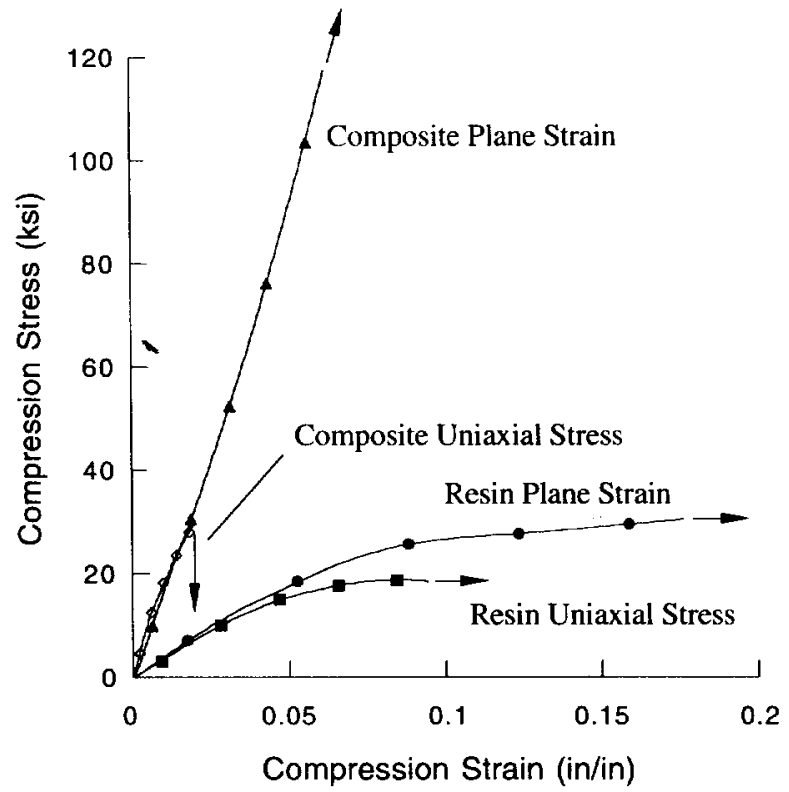

Figure 3. Response of K3B resin and IM7/K3B composite under plane-strain and uniaxial compression.

\section{DISCUSSION}

The carbon fiber composite examined here did not exhibit failure under either hydrostatic compression or plane-strain compression. Thus for this material and most likely for other high-modulus composite materials, the interactive strength parameters for the Tsai-Wu tensor polynomial strength theory can be defined by uniaxial strength parameters using the derived relations (14a) and (14b). This reduces the required strength parameters from seven to five in the full three-dimensional case and from six to five in the 
plane stress case. Moreover, the required strength terms are easily determined using standard tests for unidirectional properties. For the three-dimensional case, the failure criterion becomes

$$
\begin{gathered}
F_{1} \sigma_{1}+F_{2}\left(\sigma_{2}+\sigma_{3}\right)+F_{11} \sigma_{1}\left[\sigma_{1}-\frac{1}{2}\left(\sigma_{2}+\sigma_{3}\right)\right]+F_{22}\left(\sigma_{2}^{2}+\sigma_{3}^{2}-2 \sigma_{2} \sigma_{3}+4 \sigma_{4}^{2}\right)+ \\
F_{55}\left(\sigma_{5}^{2}+\sigma_{6}^{2}\right) \leq 1
\end{gathered}
$$

To utilize this failure theory, only the five uniaxial lamina strengths corresponding to tension and compression in the longitudinal and transverse directions plus the longitudinal shear strength are required.

\section{ACKNOWLEDGEMENTS}

The authors gratefully acknowledge the support of the Office of Naval Research, scientific officer, Dr. Y. Rajapakse and the support of the Joint DoD/DOE Advanced Munitions Technology Program.

\section{REFERENCES}

1. Tsai, S. W. and Wu, E.M., 1971, A General Theory of Strength for Anisotropic Materials, J. Comp. Mater. 5, pp. 58-80.

2. Gol denblat, I. I. And Kopnov, V. A., 1965, Strength of Glass-Reinforced Plastics in the Complex Stress State, Mekhanika Polimerov, 1, p. 70.

3. Wu, E. M., 1972, Optimal Experimental Measurements of Anisotropic Failure Tensors, J. Comp. Mater. 6, pp. $472-489$.

4. Jiang, Z. and Tennyson, R. C., 1989, Closure of the Cubic Tensor Polynomial Failure Surface, $J$. Comp. Mater. 23, pp. 208--231.

5. Kallas, M. N. and Hahn, H. T., 1990, A Failure Criterion for Composites Under 3-Dimensional State of Stress, $35^{\text {th }}$ International SAMPE Symposium, pp. 674-686. 